\title{
EDUCATION IN RADIATION PROTECTION AND RADIATION RISK COMMUNICATION TO THE PUBLIC
}

\author{
Jozef Sabol*, Bedřich Šesták \\ Faculty of Security Management, PACR in Prague, Prague, Czech Republic
}

\begin{abstract}
The paper summarizes basic radiation protection aspects important for risk communication to the public in the case of radiation/nuclear accidents or radiological attacks. The present system of radiation protection quantities and units, as well as the associated terminology, is too complicated for those who are not professionally engaged in the field but who need to have some basic understanding of how to protect themselves and others against the harmful effects of ionizing radiation. Emphasis is placed on the education and training of members of the general public in order for them to acquire some basic understanding of radiation protection. This is important for achieving better cooperation and coordination between the public and the first responders as well as relevant authorities and stakeholders during radiation or nuclear emergency situations, where the main goal is the minimization of the consequences of such events in terms of personal exposure and the radioactive contamination of the environment.
\end{abstract}

Key words: Risk communication, members of the public, radiation emergency, nuclear accident, radiological attack, radiation protection

DOI: $10.21175 /$ RadProc.2016.15

\section{INTRODUCTION}

Radiation protection is a well-established branch of the broader area related to the use of radiation and nuclear technologies in industry, medicine, science and many other fields.

The main aim of radiation protection is to ensure the adequate safety of workers, patients and the population as well as the environment against the harmful effects of ionizing radiation and radioactive contamination. In most cases where ionizing radiation sources (radionuclides, radiation generators) and nuclear reactors are used, the health effects are very low and the associated risks are lower or comparable with the risks encountered in most industries or even in our everyday life. Only in cases of incidents or accidents may the radiation exposure reach higher levels where visible (acute) detrimental effects occur.

The effects at low exposure (normal or planned situations where everything is under control) show only a stochastic (statistical) character, i.e., the effect, mostly the development of cancer in an exposed person, appears with a certain probability which is proportional to the exposure. On the other hand, at higher exposures, (exceeding a certain relatively high threshold), deterministic effects occur. They are characterized by some specific health impairments the severity of which is proportional to the exposure. Deterministic effects occur in exposed individuals receiving high exposures.
Since exposure to high radiation doses can lead to serious health effects in people, there is some potential for misusing suitable radioactive sources for terrorist or other malevolent actions. At present, one cannot completely exclude such a situation and we have to be prepared to take appropriate effective measures in order to prevent this from happening, and, if it happens, to be ready to mitigate the impact of such an emergency.

The philosophy of protection against the harmful effects of a radiological weapon or the so-called radiological dispersive device (RDD) is essentially similar to that applied with regard to any other dangerous substance within the broad category of CBRN (chemical, biological, radiological and nuclear) group.

In order to prepare the population for a radiation or nuclear emergency, it is necessary to keep the public informed about the basic impact of any foreseeable hazardous event. This process should preferably be continuous so that members of the public have a fundamental understanding of the danger they may encounter. An informed public usually accepts more realistically an emergency than people who do not know much about the nature of the impact one may expect under such circumstances.

Terminology related to the risk has not been fully consistent and there exist many different approaches. One of them consists in perceiving the magnitude of the risk as a product of the probability that the hazard will occur and the severity of such a hazard. Thus,

\footnotetext{
*jozef.sabol@gmail.com
} 
communication about the risk is related to assessing or quantifying any hazardous situation which may potentially happen sometime in the future.

Crisis communication, on the other hand, begins when the hazard occurs. It is related to the real situation and its aim is to inform the public on specific aspects of the on-going emergency event.

\section{PUblic UNDERSTANDING OF THE QUANTIFICATION OF RADIATION HAZARDS}

To perceive the risk due to the exposure, one has to understand the origin and magnitude of the harmful effects caused by ionizing radiation emitted from radioactive substances [1].

In principle, during any radiation or nuclear emergency, persons can be affected by external penetrating radiation and by internal exposure produced by radiation emitted by radionuclides which entered the body, in particular by inhalation or ingestion.

The strength of radioactive sources is usually quantified in terms of a quantity called the activity expressed in the unit of $\mathrm{Bq}$ (becquerel) which corresponds to a very small activity ( 1 disintegration per second) and this is why prefixes such as $\mathrm{k}$ (kilo), mega (M), giga $(\mathrm{G})$ and even tera $(\mathrm{T})$ are often used to characterize high-activity radioactive sources.

The activity may also be related to the unit of volume, mass or surface, which are then expressed by the corresponding units $\mathrm{Bq} / \mathrm{l}$ or $\mathrm{Bq} / \mathrm{m}^{3}, \mathrm{~Bq} / \mathrm{kg}$ and $\mathrm{Bq} / \mathrm{m}^{2}$, respectively. Often the term radioactive contamination is used referring to a deposit of dispersed radioactive material within or on any other medium, such as air, water, food, land, structure, vehicles, or persons.

In order to have an idea of the activity of some radionuclides present in common materials or radiation sources, including radiation from natural sources, table 1 illustrates a large range as to the magnitude of these sources.

Table 1 . The activity of radionuclides present in some materials, places and substances (including a human body) and in sources widely used in medicine

\begin{tabular}{|l|l|}
\hline 1 adult human $(65 \mathrm{~Bq} / \mathrm{kg})$ & $4.5 \mathrm{kBq}$ \\
\hline $1 \mathrm{~kg}$ of coffee & $1 \mathrm{kBq}$ \\
\hline $1 \mathrm{~kg}$ of brazil nuts & $400 \mathrm{~Bq}$ \\
\hline 1 banana & $15 \mathrm{~Bq}$ \\
\hline The air in many $100 \mathrm{~m}^{3}$ European homes $(\mathrm{Rn})$ & $\mathrm{up} \mathrm{to} 30 \mathrm{kBq}$ \\
\hline 1 household smoke detector (with americium) & $30 \mathrm{kBq}$ \\
\hline Radionuclides for medical diagnosis & $70 \mathrm{GBq}$ \\
\hline Radionuclide source for medical therapy & $100 \mathrm{TBq}$ \\
\hline $1 \mathrm{~kg} 50-$ year vitrified high-level nuclear waste & $10 \mathrm{TBq}$ \\
\hline 1 luminous Exit sign (1970s) & $1 \mathrm{TBq}$ \\
\hline $1 \mathrm{~kg}$ uranium & $25 \mathrm{GBq}$ \\
\hline $1 \mathrm{~kg}$ uranium ore (Canadian, $15 \%)$ & $25 \mathrm{GBq}$ \\
\hline $1 \mathrm{~kg}$ low level radioactive waste & $1 \mathrm{GBq}$ \\
\hline $1 \mathrm{~kg}$ of coal ash & $2000 \mathrm{~Bq}$ \\
\hline $1 \mathrm{~kg}$ of granite & $1 \mathrm{kBq}$ \\
\hline $1 \mathrm{~kg}$ of superphosphate fertilizer & $5 \mathrm{kBq}$ \\
\hline
\end{tabular}

For the assessment of stochastic effects a universal quantity, the effective dose, has been introduced. This quantity depends essentially on the average doses to major individual organs and tissues in the human body. All these doses have to be weighted by relevant factors reflecting various degrees of damage initiated by different types of radiation as well as specific biological sensitivities of individual organs and tissues exposed. Although the effective dose is an excellent quantity reflecting overall stochastic effects, it cannot be measured directly by monitoring. Its value can be assessed based on the measurement of other quantities, such as the ambient dose equivalent approximating the contribution from external radiation, and the intake of activity, upon which the impact of internal contamination can be evaluated.

The information in Table 1 is supplemented by some similar data giving other examples of the situations in which we receive certain portions of radiation exposure (Fig. 1).

Table 2. Typical effective doses encountered in some common circumstances. These levels can be used as benchmarks for comparison with the levels expected in radiation emergencies

\begin{tabular}{|l|c|}
\hline \multicolumn{1}{|c|}{ Origin of exposure } & $\begin{array}{c}\text { Dose } \\
\text { (mSv) }\end{array}$ \\
\hline $\begin{array}{l}\text { Average dose to US and Czech public from all } \\
\text { sources }\end{array}$ & $5-6$ \\
\hline Inhalation of air (mainly from radon) & $1-3$ \\
\hline $\begin{array}{l}\text { Average dose to the US public from medical use of } \\
\text { radiation }\end{array}$ & 3.5 \\
\hline $\begin{array}{l}\text { Average dose to the Czech public from medical use } \\
\text { of radiation }\end{array}$ & 1.0 \\
\hline London - New York airplane roundtrip & 0.05 \\
\hline Coal-burning power plants & 0.002 \\
\hline $\begin{array}{l}\text { Average dose worldwide from nuclear weapons } \\
\text { fallout }\end{array}$ & $<0.01$ \\
\hline $\begin{array}{l}\text { Average dose to the US and Czech public from } \\
\text { nuclear power plants (NPPs) }\end{array}$ & $<0.001$ \\
\hline Nuclear fuel cycle & $<0.02$ \\
\hline Chernobyl accident (world average) & $<0.01$ \\
\hline Occupational limit for radiation workers & 20 \\
\hline Chest X-ray & 0.04 \\
\hline Shoe fitting fluoroscope (not in use now) & $1-2$ \\
\hline $\begin{array}{l}\text { CT examinations (abdomen and pelvis, repeated } \\
\text { with and without contrast material) }\end{array}$ & $10-20$ \\
\hline
\end{tabular}

To coordinate effective communication with the public in preparedness for a nuclear or radiological emergency it is necessary to educate and instruct its lay members about basic elements associated with the beneficial use of radiation and nuclear technologies in various areas of industry and especially in medicine. However, the public should be aware that there is never a situation characterized by zero risk.

In order to have better understanding of the contribution of different radiation sources or their applications to the average exposure of an individual from the population, Fig. 1 shows these contributions in percentage. This reflects the situation in developed countries, where the exposure due to the medical use of radiation exceeded that due to radon which until recently contributed in most countries more than 50\% of the total population exposure. 


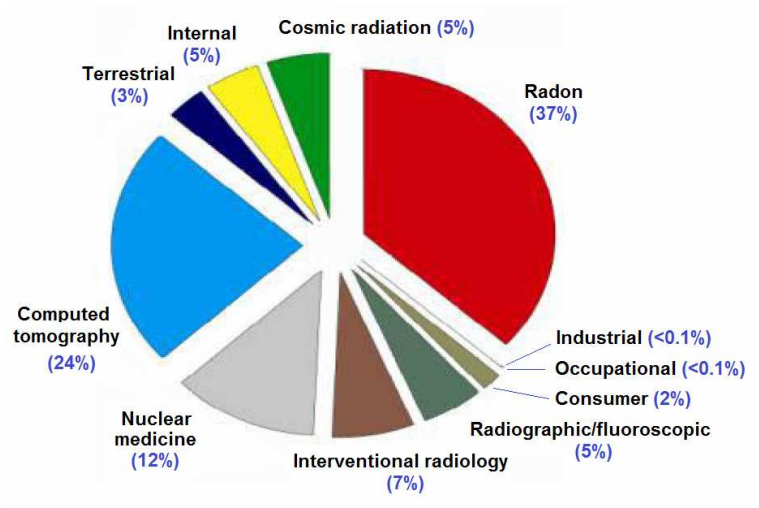

Figure 1. The typical sources of radiation exposure to members of the public. The total average exposure for the public in the Czech Republic amounts to something like $5 \mathrm{mSv} / \mathrm{y}$

As mentioned before, low-level exposure, up to approximately $100-200 \mathrm{mSv}$, results only in stochastic effects, while higher exposures can cause deterministic effects [2]. Again, members of the public should have an idea in which range exposure leads to severe health problems so that they could realistically assess the magnitude of the danger when information about possible exposure is released subsequent to an accident.

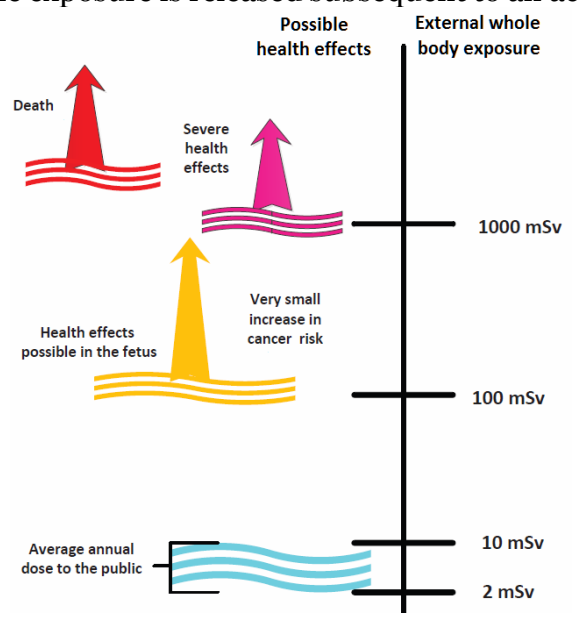

Figure 2. Health effects associated with external radiation exposure

As to the meaning of the effective dose, it presents a measure of stochastic biological effects where the corresponding probability of developing cancer is about $5 \times 10^{-3} \mathrm{~Sv}^{-1}$ [3]. In other words, if among 100 thousand persons each individual receives an effective dose of 1 $\mathrm{mSv}$, this exposure will lead to approximately 5 additional cancer cases in the exposed group. For comparison, among those 100 thousand people about 30 thousand cancer cases will develop anyway because of other agents. So, the effects or share of radiation at this low level will be responsible for a rather tiny portion of the cancer occurrence. This is why we have to assess the radiation risk in perspective and not be too afraid of low doses, although even here we are obliged to reduce their impact as much as possible. On the other hand, we should be aware that a dose of about 0:5 Sv may directly affect us and the consequences would be readily visible.

Strictly speaking, for higher exposure one has to use another quantity rather than Sv, although this is more important from an accurate scientific risk assessment perspective than in a situation where there is a need to have clear information on how much is too much. The quantification of the detriment due to harmful tissue reactions is usually better related to the dose, with the specification of irradiation conditions and the type of radiation. Recently, the unit of Gy-Eq has been introduced to take into account the specific radiobiological effectiveness (RBE) of radiation exposure at high doses applying the quantity RBE-weighted dose.

\section{THE NEED TO INFORM THE PUBLIC AND EDUCATE THE COMMUNICATORS AND SPEAKERS}

Basic information obtained during elementary and secondary education about atomic physics and the structure of matter, including the radiation emitted by radionuclides (radioisotopes), is a prerequisite for educating the public towards a variety of radiation or nuclear applications in medicine, industry and other areas, where these applications prove to be extremely useful and beneficial. It should be stressed, however, that here also, as in many other non-nuclear technologies, there exist some risks which induce certain health effects.

Those who are supposed to work with radiation professionally should receive specialized education or training at high schools or universities. The main aim of their training should be to develop skills and abilities in order to comply with regulations in order to protect themselves, other people and the environment.

Working with members of the public in order to achieve some basic understanding and awareness of the real situation associated with the use of radiation and nuclear energy is the only feasible alternative for the foreseeable future in order to satisfy an ever increasing demand for energy. Despite some nuclear accidents, such as those which occurred in Chernobyl and recently in Fukushima, more and more countries all over the world consider nuclear options in their long-term strategy. This is why it is important to continuously communicate with the public and transfer in an appropriate manner all relevant information about the present status of radiation and nuclear safety. In all communication processes one has to take into account local conditions and the opinions of people, both of which may differ substantially. In some cases, the population around the future site of such large installations as nuclear power plants sometimes, because of expected future economic benefits, may accept such facilities mainly because of some incentives and new jobs in the area.

A very specific and by far the most negative opinion of the local population is against the construction of radioactive waste repositories in their surroundings. In the Czech Republic, the current repositories which have been used for years are tolerated or accepted but it is expected that the construction of new installations for the storage and disposal of nuclear and radioactive materials would be opposed by civic activists and followers of some environmentally oriented NGOs or political parties.

Most members of the public are confused when it comes to assessing the real magnitude of the risk from news reported in the mass media. It seems that the 
complicated system of too many quantities and units used by professionals does not help, especially when journalists pick up an incorrect term; moreover, they are not always consistent and may use different numerical data in their reports related to the same event.

In keeping the public adequately informed about radiation and its effects, an important role is played by the mass media. Unfortunately, most of these media are activated only in the case of some radiation or nuclear incident or accident, when they work under time pressure and report such a situation in a way which is not consistent with the real assessment of the consequences of such emergencies.

It is obvious that not all radioactive sources are equally dangerous. Special attention should be paid to high-activity sources where categories 1 and 2 (in accordance with the IAEA categorization 4 ) should be considered in the first place. Category 1 includes sources which, if not safely managed or securely protected, would be likely to cause permanent injury to persons who handled them or were otherwise in contact with these sources for more than a few minutes. It would most probably be fatal to be close to these sources, especially if they were not properly shielded.

In specific situations we have to consider all relevant components contributing to the total exposure which include (Fig. 3):

- External exposure from contamination on outdoor surfaces, including the ground (the exposure depends on the type of radionuclide, its surface activity and geometry configuration);

- External exposure from contamination on indoor surfaces, floors, walls, furniture, etc. (the exposure depends on the same factors as above);

- External exposure from contamination on clothing and human skin (the exposure depends on the type of radionuclide and surface activity; a correction for the absorption in cloth should be taken into consideration);

- External exposure from the passing contaminated plume (the exposure depends on the type of the radionuclides and activity concentration within the plume);

- Internal exposure from inhalation during plume passage (the same as above and also physical and chemical characteristics of the radioactive substance);

- Internal exposure from the inhalation of contaminated air due to the re-suspended radioactive dust (the surface activity, characteristics of the ground as well as meteorological conditions).

It is important that the public roughly distinguish among different type of accidents or emergency events. Sometime, the impact of the RDD, or "dirty bomb", is largely overestimated while bio-agents are underestimated (Fig. 4).

\section{RECOMMENDED RULES AND REQUIREMENTS FOR RISK COMMUNICATION TO THE PUBLIC}

To construct an RDD, a terrorist group must obtain radioactive materials, use those materials to fabricate a weapon, deliver the weapon to the attack site, and detonate the device. Each of these steps suggests some specific measures that can be used to help prevent an attack. Obtaining radioactive materials requires access to the radioactive sources, which must be either purchased or stolen. This is why keeping any high-activity radioactive material under strict control is so important.
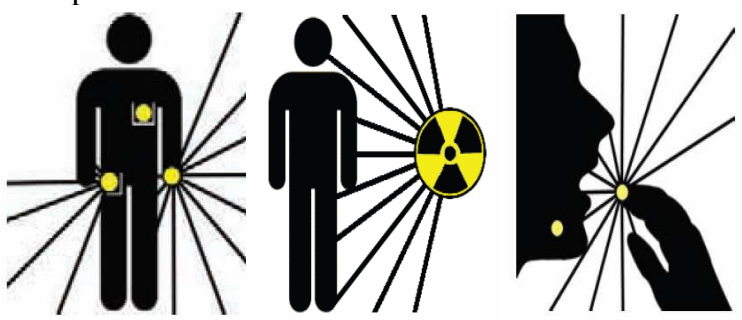

$$
\begin{array}{ccc}
\begin{array}{c}
\text { Holding or carrying a } \\
\text { high-activity source }
\end{array} & \begin{array}{c}
\text { Being close to a sealed } \\
\text { or an unsealed } \\
\text { radioactive source or } \\
\text { material }
\end{array} & \begin{array}{c}
\text { Ingesting a } \\
\text { radio-actively } \\
\text { contaminated } \\
\text { water/food or inhaling } \\
\text { contaminated air }
\end{array}
\end{array}
$$

Figure 3. Exposure pathways for radionuclides or a radioactive substance affecting the body externally or internally

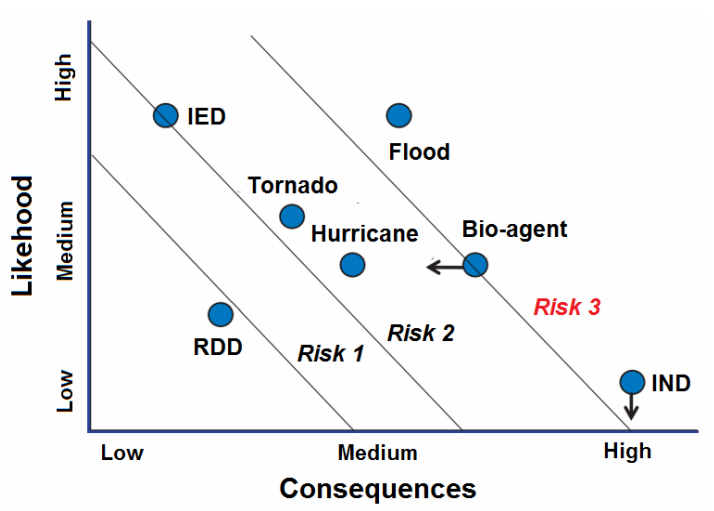

Figure 4. Examples of some risks used for prioritizing resources among all hazards (Risk $1<$ Risk $2<$ Risk 3 lines represent the equal risk, IED - improvised explosive device,

IND - improvised nuclear device, RDD - radiological dispersal device)

Radiation protection and nuclear specialists should make a concerted effort aimed at clarifying to the public the benefits and risks associated with the use of radiation and nuclear-based technologies and the concepts of resulting real hazards in order to eliminate existing myths and misunderstandings about the negative impact of these technologies. It is especially important to ensure that the public receives basic knowledge about radiation exposure and its potential harmful effects in basic and secondary schools. This should continue using the mass media, which should use lay terms to keep the public informed about the advantages of radiation and nuclear technologies while at the same time pointing out the associated risks, placing them in their proper perspective, as well as the potential danger in other industries or activities. Society has to introduce some mechanisms to avoid misusing nuclear issues in political struggles which otherwise, if not addressed, may create an atmosphere of unwarranted fears against anything containing the word nuclear. Such a misuse may adversely affect the further advancement of the use of nuclear energy, 
which so far seems to be one of the substantial sources of energy in the future.

Any such nuclear accidents like e.g. Fukushima may immediately affect public opinion, as was seen in Belgium (Fig. 5 [4]). The situation in the Czech Republic has also been influenced slightly by this event but acceptance of the use of nuclear energy for electricity production is well over $50 \%$.

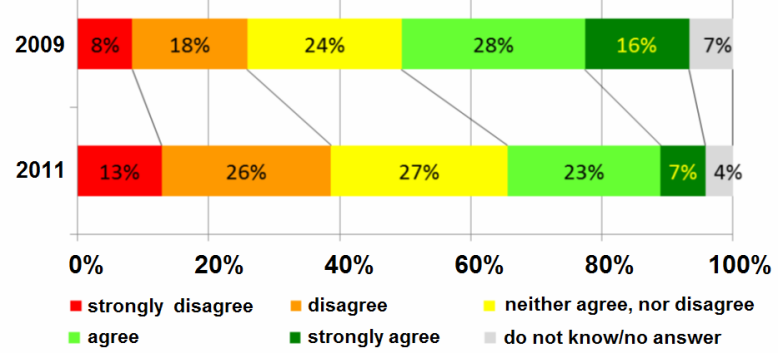

Figure 5. Illustration how people feel about the benefits of nuclear energy outweighing the disadvantages (the perception before and after the Fukushima nuclear accident)

Typical for radiological risks is also the difference between expert and lay public perception, e.g. with respect to the consequences of exposure to radiation, the safety of nuclear power plants, or nuclear waste. Many surveys have been conducted to better understand these differences. It has been concluded that, very often, lay people exhibit higher perceptions of radiological risks than the experts, who are more knowledgeable and rely on more serious and more reliable data than the public, which is often affected by tabloid and other similar information sources [5].

The public is not interested in details; it is interested in results presented in terms of safety. The public does not believe that there is nothing like zero risk for any human activity. Usually we consider as zero risk such a situation where the occurrence is so low that most members consider such danger as absolutely safe. One might compare this with the Richter scale for earthquakes, where an earthquake registering under a certain level generally does not cause any casualties or even any significant damage. In addition, there is a growing realisation that for risk communication to be effective, it should be a continual and evolving process and not simply a crisis management measure.

The recommendations and warning should specifically address the individual case. Some simple instructions provided to the public may significantly reduce the impact of an emergency. If people are near the site of the detonation of a dirty bomb or release of radioactive material, they should be advised to:

- Stay away from any obvious plume or dust cloud;

- Cover the mouth and nose with a tissue, filter, or damp cloth to avoid inhaling or ingesting the radioactive material;

- Go inside a building with closed doors and windows as quickly as can be done in an orderly manner and listen for information from emergency responders and authorities;

- Remove contaminated clothing as soon as possible and place it in a sealed container, such as a plastic bag (the clothing could be used later to estimate a person's exposure);
- Gently wash the skin to remove possible contamination.

- Those already inside an intact building should stay there and close windows and reduce outside air intake if possible.

The present technology is a relatively complex system which is not easy for an average person from the population to understand in terms of resulting risk. The technical issues inherent in risk analysis and assessment are well beyond the grasp of most members of the public. Inherently couched in quantitative language, risk as conceptualized by the technical community bears relatively little resemblance to the conceptualization of risk that is held by lay people.

The questions that risk analysis and assessment seek to answer are often very different from those to which the public seeks answers. For example, while risk analysis provides answers about the distribution of probabilities associated with a given consequence, the public typically wants to know whether or not they are safe. The peculiarity of radiological emergencies is that radiation is not detected by human sense organs, as it has neither odour, nor taste, nor colour. A human cannot assess a radiation-related threat. As a rule, the overwhelming majority of people learn of a radiation accident either from the mass media or from other second hand sources. Usually, rumours greatly exaggerate the extent of a hazard. In its turn, the mass media focus their attention on the public response to the event rather than on the actual risk level.

Some key points (summarized in [6]), based on previous experience and analysis can be formulated as follows:

- Risk communication to members of the public should be considered as one of the highest priorities. Appropriate risk communication is vital for increasing public awareness about risks in any field.

- A radiological accident provokes emotional outrage due to historical reasons: nuclear weapons used in Japan and other tests culminating in the early $196 \mathrm{~s}$.

- Risk perception depends also the socio-cultural context, where it is important to identify factors that amplify or attenuate risks and risk perceptions.

Interactive communication of information enables diverse actors to participate in discussions, prevent/ solve misunderstandings, jointly manage risks and build mutual respect.

Dirty bombs use conventional explosives to spread radioactive material. A conventional explosion may cause a number of casualties, but deterministic effects from the radiation are unlikely. The panic and fear of people on the scene, however, will probably have a more significant impact than any casualties or environmental damage. Although there is concern that terrorist groups may use dirty bombs, so far none has actually been detonated. This does not mean that we can ignore such threats.

Communication with the public is essential in order to provide them with relevant basic information about the nature and potential impact of a dirty bomb, and especially how to behave in a situation following the use of such a bomb in order to protect against exposure to 
radiation and radioactive contamination to minimize health effects.

The concerns of both society and individuals about the adverse effects from radiation are logically amplified many times when radiological terrorism is considered. The spectrum of possible events includes industrial sabotage, the use of an explosive or non-explosive radiological dispersal device, and the placement of a radiological exposure device in a public facility.

Planning is done on the basis of scenario modelling; medical response planning includes medical triage, the distribution of victims to care by experienced physicians, the development of medical countermeasures to mitigate or treat radiation injury, counselling and appropriately following and monitoring exposed or potentially exposed people, and helping the local community develop confidence in their own response plan. Optimal response must be based on the best available science. This requires scientists who can define, prioritise and address the gaps in knowledge with a range of expertise from basic physics to biology to transnational research to systems expertise to response planning to healthcare policy to communications.

Substantial collaborative efforts have to be established and maintained among relevant national agencies and between the government and international partners and local responders to ensure our collective safety. Educating the public on the potential health effects of radiation should be a long-term process and not just take place in the aftermath of a major nuclear accident.

\section{CONCLUSION}

It is important to understand when communicating the risk of radiation that, unlike the physician, the patient may not gather information from accurate sources. Instead, the patient may actually receive his/her information from other sources which convey information varying from being only somewhat inaccurate in nature to being outright wrong. This problem arises partly because of patient factors such as patient background, education and age as well as the general misinformation about radiation, which may be perpetuated in popular and populist mass media.

Thus, some members of the public may have an incorrect mental image of radiation, which may cause them quite a lot of anxiety. It depends on the long standing images and perceptions which have been present in their mind. Previous studies showed that the general public may have fundamentally different ideas about risk arising from nuclear technology as opposed to experts in the field even when nuclear technology was compared to daily activities which were quite risky in nature. While experts were of the opinion that activities arising from nuclear technology were quite safe, in the minds of quite a number of people from the lay population those very same activities were ranked number 1 in terms of risk.

Much experience has been gained in communicating risk to patients undergoing diagnostic examinations. Some of the lessons learned in the area may also apply to risk communication in other applications of radiation and nuclear technologies. The radiation risk arising from, for example, nuclear medicine investigations represent a small but manageable risk to patients and it needs to be effectively communicated to them.

Everything suggests that communication with the public cannot be limited only to the relationship between radiation and nuclear emergencies, but it should become a continuous process that educates the population about the safe use of radiation and nuclear technologies which are beneficial for society, although their implementation should be strictly regulated and controlled in order to maintain trivial risk in normal situations and to minimize the exposure to people and the impact on the environment to the lowest level compatible with the current international standards.

The stigma associated with anything recalling the name nuclear is usually vigorously cultivated by anti-nuclear activists and even some politicians. Their impact has to be neutralized by viable public relations actions which should be organized by national nuclear regulatory authorities in close cooperation with schools and universities and especially with builders and operators, who should directly participate in public relations and education.

Understanding risk perception plays a key role in developing risk communication, and ongoing communication will surely make the crisis communication that takes place after an accident more efficient. Risk perception, as an essential social and psychological phenomenon, is influenced by decision-making at individual, societal and cultural levels. Some research on risk communication suggests that the exposure to a risk could directly stimulate a person to seek more information.

Any nuclear accident or radiological emergency has an immense impact on public opinion and often lead to political discussions about the use of nuclear energy for power generation [5]. In this context, the media play an influential role in shaping public opinion about nuclear technologies. The media also have the power to influence people's opinions and even perceptions of various potential dangers. Many studies suggest that the salience of issues reported in the media influences the opinion of members of the public and even their behavior. When the mass media intensively report on a certain topic, the people receiving such information consider the topic as important and began to pay more attention to it. Moreover, the results of political and risk research show a strong correlation between the media and public priorities.

\section{REFERENCES}

1. J. Sabol, P.S. Weng, Introduction to Radiation Protection Dosimetr, Singapore, Singapore: World Scientific, 1995

2. EPR-Public Communications 2012: Communication with the Public in a Nuclear or Radiological Emergency, Vienna, Austria: IAEA, May 2012

3. "ICRP Publication 103: The 2007 Recommendations of the International Commission on Radiological Protection," J. Valentin, Ed., Ann. ICRP, vol. 37, no. 2-4, 2007

4. T. Perko, "Modelling Risk Perception and Risk Communication in Nuclear Emergency Management: An Interdisciplinary Approach," Ph.D. dissertation, Univ. Antwerp, Belgium, 2012 
5. J. Sabol, B. Šesták, Communication with the Public in Radiation Protection or Nuclear Safety and Security, in Proceed. ENS Conf., Marseille, France, May 11-14, 2014, pp. $150-157$

6. A. Sato, "Understanding Effective Risk Communication in the Context of a Radiological Accident," Fukushima Glob. Comm. Prog., Work. Pap. Ser., no. 7, Oct 2015 